\title{
Combates pelo cinema: da importância de ver, ouvir e ler narrativas audiovisuais na escola
}

Fights for cinema: the importance of seeing, listening to and reading audiovisual narratives in school

Elsa Carneiro Mendes - Plano Nacional de Cinema elsa.mendes@pnc.gov.pt https://doi.org/10.26619/978-989-9002-14-2.4

\begin{tabular}{|c|c|c|}
\hline $\begin{array}{c}\text { Recebido / Received } \\
26.05 .2020\end{array}$ & Aceite / Accepted & $\begin{array}{c}\text { Publicado / Published } \\
29.05 .2020\end{array}$ \\
\hline
\end{tabular}

Como citar este capítulo / How to quote this chapter:

Mendes, E. C. (2021), "Combates pelo cinema: da importância de ver, ouvir e ler narrativas audiovisuais na escola". In Lourenço, J. \& P. Lopes (eds.), Comunicação, Cultura e Jornalismo Cultural (pp. 71-92). Lisboa: NIP-C@M \& UAL, disponível em https://repositorio.ual.pt/handle/11144/4752 DOI https:// doi.org/10.26619/978-989-9002-14-2.4

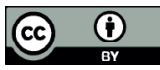




\section{Resumo}

Divulgar a cultura do cinema e audiovisual junto das comunidades educativas constitui-se, em nosso entender, matéria particularmente relevante nas sociedades atuais. Estando em curso um conjunto alargado de políticas educativas públicas que incentivam a valorização da fruição cultural por parte das crianças e dos jovens, reforçar a visibilidade dos sistemas de mediação cultural disponíveis junto das comunidades educativas pode tornar-se uma medida decisiva de estratégia cultural. No concreto, é essencial aliar a importância pedagógica das narrativas audiovisuais ao papel formativo que o jornalismo de cinema pode assumir, quer como ferramenta privilegiada para eliminar fronteiras entre cultura e educação, quer como mediador singular da divulgação de fenómenos provenientes da cultura popular e massificada, intrínsecos à cultura do cinema e audiovisual, quer ainda como instrumento que possibilita, cabalmente, a democratização nesta área específica da cultura. 


\section{Abstract}

Disseminating the culture of cinema and audiovisual among educational communities is, in our view, a particularly relevant material in today's societies. With a wide range of public education policies underway that encourage the appreciation of cultural enjoyment by children and young people, enhancing the visibility of cultural mediation systems available to educational communities can become a decisive measure of cultural strategy. In concrete, it is essential to combine the pedagogical importance of audiovisual narratives with the formative role that cinema journalism can assume, either as a privileged tool to eliminate borders between culture and education, or as a singular mediator of the dissemination of phenomena from popular and mass culture, intrinsic to the culture of cinema and audiovisual, or as an instrument that fully enables democratization in this specific area of culture. 
Embora o cinema se consubstancie fundamentalmente como uma expressão artística, é verdade que na sua vertente mais multifacetada e popular se organizou segundo o modelo de produção industrial, através de todos os seus recursos e procedimentos, mais focado nas possibilidades imediatas do lucro, e menos no poder libertador que a arte detém junto dos seres humanos. Mesmo assim, ao longo da sua história, o facto é que o cinema industrial (aqui incluímos naturalmente a gigantesca produção das indústrias de Hollywood) produziu obras imensas, muitas com marca autoral e grande nível de qualidade nas componentes de narratologia, argumento, fotografia, som, mise-en-scène, etc., comentando a cultura tradicional e clássica, interagindo com ela, alargando significativamente a experiência e a transmissão da denominada alta cultura a um maior número de pessoas e a mais grupos sociais. A título de exemplo, sabemos como, ao longo de toda a primeira metade do século XX, no âmbito do cinema produzido em Hollywood, a nova arte e indústria propôs revisitar a Antiguidade Clássica e a Idade Média, através de um gosto evidente pela manipulação de múltiplas tradições (literárias, pictóricas, teatrais, operáticas), e apropriou-se de uma teia complexa de fontes que contribuíram para diversificar a linguagem cinematográfica e, na nossa perspetiva, a transformaram numa torrente de processos de afirmação da Cultura Contemporânea Ocidental. Em meados dos anos sessenta e nos anos setenta, o aparecimento de dois textos de Umberto Eco, um sobre James Bond e outro sobre Superman, refletem precisamente esse olhar destinado a valorizar as referências da cultura popular. $\mathrm{Na}$ altura conotado exclusivamente com a faceta 
de entretenimento, atualmente o estudo do fenómeno Bond e da evolução da sua estrutura narrativa maniqueísta no cinema, é uma matéria interdisciplinar que cruza Estudos de Cultura/História da Cultura/Filosofia Política/Estudos Fílmicos/Estudos Visuais/Jornalismo Cultural, trabalhando o fenómeno como uma representação cultural complexa e mutável.

Este reconhecimento é essencial: é tão importante conhecer os universos e comportamentos da cinefilia mais tradicional, como os comportamentos heterogéneos dos chamados universos de fãs, que, tal como os primeiros, também desenvolvem consumos distintos de cinema (muitas vezes, os chamados cult movies) e movem-se, paralelamente em comunidades digitais e outras, com um entusiasmo extraordinário (Chinita, 2016). Vale a pena ir ainda mais longe no estudo dos fenómenos da cultura popular e articulá-los com as mais recentes formas de realidades transmedia, na medida direta em que sabemos que a experiência dos jogos de entretenimento, tão apreciada pelos jovens, obedece a múltiplas agendas políticas ao mesmo tempo que proporciona "valuable lessons in civics» (Geraci e Recine, 2014). O mesmo se passa com o universo emergente dos making of, dos trailers e outros canais digitais de divulgação de informação/conteúdos relacionados com cinema, proporcionando aos jovens «uma experiência mais imersiva e sensorial» (Robert, 2018: 43), cujos produtos deveriam merecer cada vez mais uma atenção analítica por parte da escola.

Ao proporem uma visão mais imersiva da vida, estes territórios em que se movem as narrativas audiovisuais (o cinema em des- 
taque) e os produtos culturais afins reservam-nos intacto um campo humano fundamental, eu diria mesmo sagrado: a subjetividade. Felizmente para todos nós, um filme é um engano, e não uma coisa exata. Insisto neste reconhecimento da subjetividade como um fenómeno intrínseco da cultura humana, numa altura em que seria elementar normalizar a ideia de que a manipulação audiovisual (elemento de subjetividade) é intrínseca às narrativas audiovisuais e aos seus universos (Rocha, 2020), e valorizar cabalmente o trabalho de uma das profissões mais emblemáticas e misteriosas do mundo do audiovisual: a montagem/edição. Infelizmente, a simples palavra manipulação infunde um medo quase paralisador em muitos contextos, que nos impede de perceber a natureza criadora e, no caso do cinema, artística, que está no cerne do exercício de montagem. Mas é exatamente por aí que deveríamos começar a normalizar conceitos, aceitando a verdade de que «montar é manipular (...) tudo o que fazemos é manipular», eis o sentido do testemunho de Michael Kahn, uma autoridade na matéria ${ }^{1}$. Falta-nos valorizar isto. Se aceitarmos que os processos mediáticos são em boa medida narrativas subjetivas, alargamos a nossa perspetiva, e podemos finalmente começar a falar sobre o audiovisual.

Na medida em que a noção de imagem fílmica, cultura e cultura visual se constituem como um todo indissociável (Carlos, 2017: 555), defendemos que é necessário conhecer e cruzar matérias provenientes de universos mais imersivos de que os filmes são

1 Michael Kahn (n. 1935) - Montador norte-americano. Destacamos a colaboração notável com Steven Spielberg, em Close Encounters of the Third Kind, Raiders of the Lost Ark, Schindler's List e Saving Private Ryan, entre muitos outros trabalhos. 
apenas uma das facetas. Em nosso entender, vivemos um período de transformações sem precedentes, e, eventualmente, estamos a presenciar a maior migração de suportes/formatos técnicos de comunicação humana de que temos memória. A esta luz, é importante reconhecê-las como material de estudo e experimentação, e é fulcral recorrer aos mecanismos de mediação que os comentam sistematicamente e nos ajudam a entender processos e múltiplos sentidos possíveis das chamadas indústrias culturais destinadas à sociedade massificada. Nas últimas décadas, a investigação académica na matéria tem vindo continuamente a reforçar, quer a especificidade do jornalismo de cinema enquanto objeto de estudo académico (Lourenço, 2016), quer a perspetiva de articulação inadiável do trabalho das escolas com a cultura dos media, nomeadamente do jornalismo (Flor, 2019).

A seu tempo, João Bénard da Costa sublinhou como a crítica fílmica e cinematográfica foi «o astrolábio e o quadrante orientadores nas descobertas do território do cinema e quem ergueu os padrões da sua cartografia de cinéfilo.» (Nogueira, 2002: 7), confirmando-nos como podemos ver um filme duas ou três vezes, interiorizar uma perspetiva sobre o filme, e como podemos evoluir para uma visão inteiramente nova sobre ele após algumas leituras críticas complementares. Julgamos que esse foi o programa original do jornalismo cultural, cuja «intenção era a de não restringir a uma elite a esfera das artes, da filosofia e da literatura» (Melo, 2010: 5), assumindo funções de mediação social através da sua capacidade em simplificar para diversos públicos os múltiplos níveis de comunicação da arte. Edgar Morin 
sintetizou cabalmente esta perspetiva ao dizer que a função do jornalismo cultural é revelar de forma clara e acessível «que, em toda grande obra, de literatura, de poesia, de música, de pintura, de escultura, há um pensamento profundo sobre a condição humana» (Melo, 2015: 6). Para nós, a apropriação de uma cultura cinematográfica, a condição cinéfila ou estatuto de fã de cada um de nós, são elementos indissociáveis da sobreposição do ato de ver filmes e do consumo de textos e outros materiais que discorrem sobre os filmes e os interpretam. E no caso do universo dos fãs, por detrás do que parece ser um superficial universo das celebridades ou dos super-heróis (tão do agrado dos jovens), há todo um separar de águas que é preciso fazer, com o contributo de um determinado tipo de jornalismo de cinema que nos ajuda a perceber a receção a um filme, as razões estéticas e técnicas das escolhas realizadas, a validade de comparar filmes entre si e com as diversas produções oriundas da cultura, de uma forma geral.

Gostavamos de partir de um exemplo concreto, proporcionado pela recente conjuntura pandémica, abrindo a lente para propostas de análise fílmica em que os média e o jornalismo de cinema podem funcionar como importante auxiliar do trabalho que os professores desenvolvem com alunos. A propósito deste contexto recente, se uns defendem que estamos a viver num admirável mundo novo e distópico (a expressão foi precisamente colhida num título de artigo assinado por José Carlos Maltez na Take Magazine) (Maltez, 2019: 91), outros recusam essa impressão, afirmando não conseguir «associar o momento em que 
vivemos a um qualquer filme distópico» (Ribas, 2020: 60). Este contraditório pode ser um bom pretexto e oportunidade de explicar às crianças e aos jovens a ambiguidade e poder evocativo das imagens e argumentos de ficção, nomeadamente da ficção científica, sobre a ameaça à humanidade e/ou a extinção humana que proliferaram nos canais televisivos (muitas produções cinematográficas), procurando contextualizar a «normalização» e proliferação desse tipo de ficções em determinados períodos. Mais uma vez, recorremos a Eco: «(...) a boa fiç̧ão científica é cientificamente interessante não porque fala de prodígios tecnológicos [...], mas porque se apresenta como um jogo narrativo sobre a própria essência de toda a ciência, isto é, sobre a sua conjeturabilidade» (Piassi \& Pietrocola, 2009: 528).

Há um potencial educativo na ficção (Moreira \& Rodrigues, 2019), e é exatamente aí que nos focamos: as ficções mais arrebatadas ou irreais têm um papel social que é preciso valorizar, e podem, e devem, ser estudadas e refletidas com os alunos. Fantasias audiovisuais sobre o fim (apocalipses, milenarismos, profecias e escatologias), e, mais especificamente, o imaginário pandémico que agora nos assola, são, mais do que nunca, matéria académica e de divulgação urgente, sob as mais diversas perspetivas, quer para o grande público, quer para os alunos e para os professores, moldando novos heróis, colocando arrojadas hipóteses científicas ao serviço de narrativas ficcionais, criando múltiplos "fios» condutores subjetivos de leitura do nosso imaginário coletivo e da História (Lynteris, 2019). 
Com efeito, uma das receitas mais eficazes para sossegar as nossas utopias coletivas resulta, no geral, da partilha de determinadas emoções através da arte (que expõe e normaliza, por assim dizer, as nossas fraquezas), como bem defendeu João Lopes ao referir-se ao "cinema da nossa vulnerabilidade» (Lopes, 2020). Nos casos de alguns filmes ancorados em temáticas epidémicas, como O Sétimo Selo (1957), de Ingmar Bergman, Morte em Veneza (1971), de Lucchino Visconti, ou o "asséptico» (Câmara, 2008), «inteligente e frio» (Mourinha, 2008) Ensaio Sobre a Cegueira (2008), de Fernando Meirelles, as narrativas são verdadeiros dramas existenciais que abrem para leituras culturais mais amplas, onde ressoa toda a História da Civilização europeia, e são, muito menos, histórias à volta da paranoia gerada pelo vírus ou sobre a heroicidade dos médicos que os tratam. Mas em casos como os dos perturbadores Fora de Controlo (1995), de Wolfgang Petersen, o genial 12 Macacos (1995), de Terry Gilliam (baseado em La Jetée, de Chris Marker), que trabaIha uma questão humana tão importante como o livre arbítrio, Contágio (2011), de Steven Soderbergh (filme tornado viral em 2020, por razões óbvias), ou WWZ - Guerra Mundial (2013), de Marc Forster, um filme que coloca a tónica nas diversas respostas mundiais e locais a um contexto pandémico, todas estas histórias congregam medos e paranoias coletivas que refletem uma «ansiedade biológica» (Rodrigues, 2010: 209), e remetem para a massificação das sociedades e para militarização das situações, sublinhando a potencial aliança negativa entre a ciência, poder político e poder militar. Todos estes filmes legitimam de alguma forma o poder militar, apesar do invólucro ficcional ser mais 
imediato e próximo das narrativas de super-heróis, e entronizarem um tipo específico de herói: o epidemiologista/virologista e/ou pessoas com doenças que as diferenciam e marginalizam socialmente, e que podem ter potencialidades acrescidas de sobrevivência em face da doença coletiva.

Os exemplos abundam na ficção cinematográfica, e muitos deles mereciam ser vistos e estudados nas escolas, também a partir do auxílio do jornalismo de cinema, quer clarificando a importância de levar estes filmes a vários públicos, quer divulgando a reação da indústria do cinema e dos públicos às epidemias. Como referimos há pouco, para credibilizar um objeto de estudo desta natureza, é preciso convocar todas as camadas de leituras sociológicas possíveis que se escondem por detrás de um invólucro de aparente superficialidade ou conforme a agenda do momento. Dois ou três contributos dos críticos de cinema a este propósito deixam pouca margem para dúvidas, em matéria de importância da crítica cinematográfica para nos orientar a todos: leiam-se artigos assinados por Peter Bradshaw e Mark Kermode (no The Guardian), 12 Monkeys, assinado por Roger Erbert (em Rogererbert.com) , A Time Traveler With Bad News - Twelve Monkeys, assinado por Janet Maslin (no The New York Times), ou os mais recentes Lessons for the Movie Industry from the 1918 Influenza Pandemic, assinado por Richard Brody (no The New Yorker), ou The 21st century plague: Cinema in the age of COVID-19, assinado por Wheeler Winston Dixon, (em Senses of Cinema), para percebermos as utilidades e vantagens de levar aos alunos ideias e conceitos sobre como é que o cinema filma 
comportamentos coletivos, a partir de perspetivas críticas colocadas pelo jornalismo de cinema e outros recursos mediáticos online. Entre nós, ainda que num campo distinto dentro da temática das contaminações, e sem qualquer ambição de uma sistematização mais aprofundada, mas que reputamos de urgente, lembramos o artigo de Sara Quelhas na revista online Metropolis (Quelhas, 2019: 178), a propósito de um sucesso televisivo recente da HBO: Chernobyl (2019), de Johan Renck, com argumento de Craig Mazin. Um tema recorrente em salas de aula, sublinhou Sara Quelhas, valorizando precisamente um dos aspetos mais interessantes que o tema convoca: a conivência entre elementos da comunidade científica, as estruturas do poder político, civil e militar, e a manipulação que o poder político encena para manter a população ignorante e passiva, fornecendo fake news ou subtraindo informação através dos media. Dan Schindel também se referiu à oportunidade do subplot sobre fake news a propósito de Contágio, muito antes de ser ter começado a falar disso (Schindel, 2020). Agora, sob os efeitos recentes da pandemia mundial de Covid19, para além de elencar alguns dos títulos mais fortes na matéria, João Antunes, no Jornal de Noticias (Antunes, 2020) alertou para várias questões que, do nosso ponto de vista, interessa abordar com jovens: a capacidade de a arte/ a ficção antecipar a realidade com algum rigor, um dos elementos mais perturbadores do poder da ficção. Dan Schindel já sublinhara este aspeto da eficácia dos detalhes, a propósito de Contágio, ao dizer: "It's the specific details, though, like a scene that'll make you conscious of how often you touch your face (...) that truly resonate» (Schindel, 2020). Parafraseamos 
João Lopes, quando, a propósito deste tipo de filmes, ele valoriza a intensidade com que a ficção consegue reter facetas constituintes do nosso mundo hipertecnológico (a desinformação, por exemplo), e consegue evidenciar a dimensão da vulnerabilidade humana, não obstante estas obras aparentarem ser uma «variação realista sobre um modelo típico das aventuras de super-heróis» (Lopes, 2020). Se, no caso de WWZ-Guerra Mundial, o apocalipse biológico se apresenta como pretexto para um drama familiar típico cujo tema de fundo é a «consistência e os valores da comunidade humana» (Lopes, 2013) numa época de uma globalização em que cada vez acreditamos menos, em Contágio há uma dramática perspetiva voyeurística que atravessa todo o filme, que confronta a privacidade familiar e a solidão, e que se concretiza através de estratégias cinematográficas: menos iluminação, enquadramentos com portas, janelas, objetos, som baixo, o uso de shallow focus (que nos concentra nos personagens principais, isolando-os, mesmo quando está uma multidão presente) e de follow shots (valorizando a experiência das personagens e não os elementos catastróficos). Em narrativas audiovisuais desta natureza, precisamente pelas ligações que é preciso estabelecer com a ciência e/ou com premissas científicas (Antunes, 2020), é extremamente importante sublinhar a especificidade do argumento fílmico, o valor e a natureza da escrita ficcional cinematográfica aliada às restantes características técnicas de escolha de imagens, sons e narrativa filmica, que é preciso distinguir da estrita verdade científica. É necessário confrontar os jovens (e o público de cinema no geral) com a noção de que há um momento em que a «scientific accuracy is sacri- 
ficed, and cinematic laws prevail» ( Pappas, Seitaridis, Akritidis, \& Tsianos, 2003), porque, a partir de um certo ponto, mesmo que a narrativa audiovisual não corresponda a padrões de exatidão médica e científica, ela tem ritmos internos que é preciso respeitar, e, em sociedades democráticas, é ético não controlar os conteúdos de um filme. Em síntese, e sem recorrer aos clichés tradicionalmente utilizados no filme Catástrofe, a análise do caso do filme de Steven Soderbergh em articulação com a mediação do jornalismo de cinema, constitui-se como um exemplo de excelentes potencialidades pedagógicas. O que importa é aprender a lidar com as imagens. Mais: «delas devemos manter uma distância de segurança», como nos diz Daniel Ribas. (Ribas, 2020: 61).

Não obstante os inúmeros exemplos que poderíamos continuar a fornecer sobre a eficácia do jornalismo de cinema ou do recurso a mecanismos mediáticos específicos sobre a matéria, para sugerir interessantes pistas de trabalho aos alunos, infelizmente este não é um dado adquirido. $O$ conhecimento dos processos de construção de sentido no universo das artes que concorrem para o cinema, e, de uma forma geral, os mecanismos de produção de sentido no audiovisual não são reconhecidos como tão fulcrais para a formação integral dos jovens, como o é a aprendizagem de outras disciplinas que integram o currículo. Provavelmente já o percebemos, mas ainda não fomos capazes de mudar significativamente as coisas a esse nível nos sistemas educativos, articulando mais o núcleo dos currículos disciplinares com a cultura dos mass media e integrando nesse núcleo 
disciplinar a aprendizagem de um qualquer tipo de iniciação à criação/produção de indústrias culturais e ao universo da montagem/edição audiovisual, desde a mais tenra idade. Ainda não concretizámos mudanças suficientes que mostrem que valorizamos o estudo da imagem (das artes plásticas ou da imagem em movimento) a ponto de a equiparar ao texto escrito (ainda todo-poderoso) (Duarte, 2002: 17) e de a colocar no núcleo de um currículo contemporâneo para todas as idades. Assim, não conseguimos avaliar coletivamente o caráter potencialmente pedagógico da ficção audiovisual (cinema, TV, videogame...), não somos capazes de reconhecer coletivamente a imagem fílmica como dimensão essencial da cultura contemporânea (a par das artes plásticas, da música e da literatura, mas essas estão sedimentadas nos currículos disciplinares), nem capazes de the reconhecer o estatuto de dispositivo pensante, quanto mais pedirmos ao sistema para tornar análise e a experiência fílmica e audiovisual uma coisa séria.

Se isto é crucial no que respeita ao conhecimento de processos de produção, também o é no que respeita a uma coisa tão simples quanto a fruição cultural. A fruição cultural é uma prática essencial para as crianças e os jovens, e ver/ouvir em casa um filme, uma peça de teatro ou um concerto, e fazê-lo repetidas vezes, está longe de ser um ato passivo e não é apenas uma questão de entretenimento. Sou muitas vezes confrontada com a mesma pergunta desinteressante quando defendo isto: mas é só isso? é só ver cinema? é só ouvir ópera? é só ver teatro? Frequentemente, a única coisa que parece ser importante para 
uma grande parte dos interlocutores é fazer cinema, fazer música, fazer teatro, não se identificando como elemento educativo fundamental e basilar da promoção dos níveis de consumo cultural uma coisa tão evidente como o ato continuado de fruição cultural e artística.

Enquanto professora, lembro-me perfeitamente de, em 2014, ter alunos finalistas de 12. ano (área de Humanidades), a quem mostrava frequentemente excertos de filmes, de videoclips, de programas televisivos, de animações, que me perguntaram um dia: mas é possível seguir esta área, estudar estas coisas? Tinham feito 12 anos de escolaridade obrigatória e não tinham sido minimamente expostos a esta área do conhecimento enquanto tal, porque, globalmente, o sistema mantém imutáveis todo o tipo de elitismos culturais, não ultrapassou o mito de que a arte é para quem tem talento, não encarou de frente que a arte é uma linguagem acessível para todos, com os seus processos próprios de produzir e pensar, tanto numa lógica de formação de artistas, como de educação de públicos. Em suma, a arte é uma linguagem que todos devemos aprender, embora nem todos a venham a seguir profissionalmente.

A realidade é que, na larga maioria dos casos (e há exceções válidas, é claro), a escola apenas pede ao cinema e audiovisual uma "pedagogização» (Almeida, 2017), integrando-os nos currículos escolares, classificando-os, dividindo-os, reduzindo-os, transformando-os e/ou usando-os em produtos ao serviço de propósitos didático-pedagógicos (Almeida, 2017). Ora, o conhe- 
cimento e a experiência dos processos construtivos da narrativa fílmica e audiovisual promovem o apuramento de competências de leitura, visuais e sonoras e, porque eles são, antes de mais, artefactos de cultura e criação, não podem ser utilizados apenas como recursos didáticos e ilustrativos, mesmo que nessa vertente existam experiências sobejamente válidas que não questionamos. Em 2012, Martin Scorsese confessou numa entrevista como ocorreu o seu encontro com o cinema, ainda muito novo, revelando que descobrira ao vê-lo que,

"there was another kind of intelligence that was trying to tell a story through, where the director, the writer and the cinematographer, where they were focusing your eyes (...) I think you really need to know how ideas and emotions are expressed through a visual form. Now that form could be video, or film (...) it still has the same rules (...) the same vocabulary (...) the same grammar (...) panning left or right, tracking in or out, booming up and down, intercutting a certain way, use of a close-up, as opposed to a medium shot (...) and I think we have to begin to teach our younger people how to use this very powerful tool" (Scorsese: 2012).

Vivendo nós numa era de cultura visual, ou seja, uma cultura que institui a subjetividade visual e sonora em permanência no nosso quotidiano (fenómeno reforçado pelo aumento do consumo de transmissões televisivas e/ou em plataformas, face à recente conjuntura pandémica), entendemos que o textofilmico, as narrativas audiovisuais e os mecanismos mediáticos de intercessão para o seu entendimento devem ser apropriados 
como representações de saberes passíveis de criação, reflexão e partilha pelos estudantes. Por outras palavras, o audiovisual deve ser introduzido e ensinado nas escolas desde a mais tenra idade. Temos a conviç̧ão de que é urgente pensar no alargamento da oferta da cultura do cinema e, do ensino de cinema e audiovisual aos diversos níveis de ensino, disseminá-los numa perspetiva nacional, e esse passo só pode ser desenvolvido se se estabelecerem canais de comunicação fortes entre o setor do cinema, a investigação académica, a comunicação social do cinema e os diversos setores da educação implicados no desenho de currículo (estamos a falar de políticas públicas), viabilizando o desenvolvimento desta área específica, de forma que possa chegar aos vários níveis da escolaridade.

Finalizamos, retomando as palavras de José Carlos da Costa Ramos (Simões, 2017: anexos), que citamos:

"Tem a ver com a integração consistente da imagem e das questões da imagem nos currículos escolares. Eu creio que nós hoje temos uma necessidade absoluta, desde o ensino primário, de criar literacia visual e sobretudo consciência crítica relativamente à imagem. (...) em termos de política geral é isto, é uma política de literacia visual. (...) as pessoas na área da cultura tinham a obrigação de começar uma conversa com a Educação para perceber como é que isto se faz. Acho que é uma responsabilidade nacional."

Subscrevemos o desafio, posicionamo-nos enquanto observadores interessados, e precisamos de interlocutores nesta matéria. 


\section{Bibliografia}

Almeida, R. de (2017). "Cinema e Educação: fundamentos e perspetivas", Scielo, Educ. rev. vol. 33, Belo Horizonte, disponível em: $\quad$ http://www.scielo.br/scielo.php?script=sci arttext\&pid=S010246982017000100107\&lng=pt\&t|ng=pt.

Antunes, J. (2020). "Vírus e pandemias: os filmes antes da realidade".,Jornal de Notícias, 20 de março, disponível em: https://www.jn.pt/artes/virus-e-pandemias-os-filmes-antes-darealidade-11959222.html.

Brody, R. (2020). "Lessons for the Movie Industry from the 1918 Influenza Pandemic", The New Yorker, 17 de março, available in: https://www.newyorker.com/culture/the-front-row/lessons-for-themovie-industry-from-the-1918-influenza-pandemic.

Câmara, V. (2008). "Ensaio sobre a Cegueira”, Público, 13 de novembro, disponível em: https://www.publico.pt/2008/11/13/culturaipsilon/ critica/ensaio-sobre-a-cegueira-1654544.

Carlos, E. (2017). "Sobre o uso pedagógico da imagem fílmica na escola", ETD-Educação Temática Digital. Campinas, SP, v.19 n.2.

Dixon, W. W. (2020). The 21st century plague: Cinema in the age of COVID-19. Senses of Cinema, abril, available in: http://sensesofcinema. $\mathrm{com} / 2020 /$ feature-articles/the-21st-century-plague-cinema-in-theage-of-covid-19/.

Chinita, F. (2016). Meta-cinematic Cultism: Between High and Low Culture, disponível em https://pdfs.semanticscholar. org/a37d/6d654156cba866f3e728a6ff8b494125d1af.pdf? ga $=2.178467300 .1991101775 .1589130785-1036741966.1589130785$

Duarte, R. (2002). Cinema \& Educação. Belo Horizonte: Autêntica.

Flor, A. (2019). "Aprender com os jornais funciona melhor com as mãos na massa", Público, 6 novembro, disponível em: https://www.publico. pt/2019/11/06/sociedade/noticia/aprender-media-funciona-melhormaos-massa-1892664. 
Geraci, R. M. \& Recine, N. (2014). "Enlightening the Galaxy: How Players Experience Political Philosophy in Star Wars: The Old Republic". Games and Culture, Vol. 9(4), pp. 255-276, available in: https:// journals.sagepub.com/doi/abs/10.1177/1555412014538810.

Gilbey, R. (2020). "When old films go viral: how coronavirus gave Contagion an unexpected afterlife", The Guardian, 30 janeiro, available in: https://www.theguardian.com/film/2020/jan/30/what-can-welearn-about-coronavirus-from-watching-contagion

Lynteris, C. (2019). Human Extinction and the Pandemic Imaginary. New York: Routledge.

Lopes, J. (2020). Epidemias no grande ecrã: o cinema da nossa vulnerabilidade", Diário de Notícias (DN), 12 fevereiro, disponível em: https://www.dn.pt/1864/epidemias-no-grande-ecra-o-cinema-danossa-vulnerabilidade-11785500.html

Lopes, J. (2013). Os zombies também são globais. 19 junho 2013, disponível em: https://www.rtp.pt/cinemax/?t=Os-zombies-tambemsao-globais.rtp\&article $=9150 \&$ visual $=2$ \&layout $=35 \& \mathrm{tm}=52$

Lourenço, J. (2016). Um Olhar sobre o jornalismo de cinema na televisão portuguesa - O caso do Cinebox da TVI24. Lisboa: ESCS.

Maltez, J. C. (2019). “O admirável mundo novo das distopias: da literatura ao ecrã". Take, 51, pp. 90 - 97, disponível em: https://issuu. com/take/docs/take51

Melo, I. A. (2010). Jornalismo Cultural: Pelo encontro da clareza do jornalismo com a densidade e complexidade da cultura, disponível em: http://www.bocc.ubi.pt/pag/melo-isabelle-jornalismo-cultural.pdf

Moreira, J. A. \& Rodrigues. E. (2019). “Potencialidades do Cinema de Fiç̧ão Científica em Contexto de Reclusão e o seu Impacto na Construção de Comunidades de Aprendizagem". Icono 14, 17 (2), pp. 130-153, disponível em: https://www.redalyc.org/ jatsRepo/5525/552559704009/movil/index.html 
Mourinha, J. (2008). "Terra de cegos", Público, 13 de novembro:, disponível em: https://www.publico.pt/2008/11/13/culturaipsilon/ critica/terra-de-cegos-1654542

Nogueira, V. (2002). Cinema. Narratologia. Jornalismo - Um travelling pela cultura cinematográfica. Dissertação de Mestrado, Coimbra. FLUC, disponível em: https://estudogeral.sib.uc.pt/ bitstream/10316/9748/1/Nogueira\%2c\%20Ant\%c3\%b3nio\%20 Couceiro\%20da\%20Cruz.pdf

Pappas, G., Seitaridis, S., Akritidis, N. \& Tsianos, E. (2003). "Infectious Diseases in Cinema: Virus Hunters and Killer Microbes". Clinical Infectious Diseases. 37, pp. 939-42, available in: https://academic. oup.com/cid/article/37/7/939/422604

Piassi, L. P. \& Pietrocola, M. (2009). "Ficção científica e ensino de ciências: para além do método de "encontrar erros em filmes'", Educação e Pesquisa, São Paulo, v.35, n.3, pp. 525-540, set./dez., disponível em: https://www.scielo.br/pdf/ep/v35n3/08.pdf

Quelhas, S. (2019). "Chernobyl - HBO Portugal”. Metropolis, n. 69, julho, pp. 178-185.

Ribas, D. (2020). "O fim do mundo". Público, Ípsilon, 22 de maio.

Robert, S. M. (2018). O Jornalismo Cultural do PÚBLICO na Era Digital. Lisboa: FCSH, 2018.

Rodrigues, E. (2010). Alteridade, Tecnologia e Utopia no Cinema de Fiç̧ão Científica norte-americano: a Tetralogia Alien. Coimbra, Universidade de Coimbra.

Schindel, D. (2020). "Viral" Movies About Outbreaks and Pandemics to Watch While You Social Distance". Hyperallergic, março, available in: https://hyperallergic.com/547900/viral-and-disease-films-streaming/

Simões, C. (2017). O Cinema Português: entre a arte e a indústria 45 anos de políticas públicas (1971-2016). Lisboa: ISCTE, anexos. 


\section{Webgrafia}

Iniciativa 7 Dias com os Média 2020, 6 de maio, disponível em: $\underline{\text { https:// }}$ www.incode2030.gov.pt/destaque/7-dias-com-os-media

Rui Rocha, Da notícia à ficção, o poder da manipulação - algumas dicas. Edutopia, 2012, disponível em: https://www.facebook. com/102394658003236/videos/741328609992565/

Martin Scorsese on the Importance of Visual Literac, Studiobinder, 2020, available in: https://www.youtube.com/watch?v=|90ZluYvHic

Contagion, What Soderbergh's Pandemic Got Right About the Coronavirus, available in: https://www.youtube.com/ watch?v=YuZ8Xs64BEo 